\title{
Methanogenic Diversity Studies within the Rumen of Surti Buffaloes Based on Methyl Coenzyme M Reductase A (mcrA) Genes Point to Methanobacteriales
}

\author{
KRISHNA M. SINGH ${ }^{1}$, PARESH R. PANDYA ${ }^{2}$, SUBHASH PARNERKAR ${ }^{2}$, AJAI K. TRIPATHI $^{1}$, UMED RAMANI ${ }^{1}$, \\ PRAKASH G. KORINGA ${ }^{1}$, DHARAMSHI N. RANK ${ }^{3}$, CHAITANYA G. JOSHI ${ }^{1}$ and RAMESH K. KOTHARI ${ }^{4}$
}

\author{
${ }^{1}$ Department of Animal Biotechnology, College of Veterinary Science and A.H., \\ Anand Agricultural University, Anand (388 001), Gujarat, India \\ ${ }^{2}$ Animal Nutrition Research Station, College of Veterinary Science and A.H., \\ Anand Agricultural University, Anand (388 001), Gujarat, India \\ ${ }^{3}$ Department of Animal Genetics \& Breeding, College of Veterinary Science and A.H., \\ Anand Agricultural University, Anand (388 001), Gujarat, India \\ ${ }^{4}$ Department of Microbiology, Christ College, Rajkot, Gujarat, India
}

Received 3 April 2010, revised 21 June 2010, accepted 12 July 2010

\author{
Abstract
}

\begin{abstract}
Methane emissions from ruminant livestock are considered to be one of the more potent forms of greenhouse gases contributing to global warming. Many strategies to reduce emissions are targeting the methanogens that inhabit the rumen, but such an approach can only be successful if it targets all the major groups of ruminant methanogens. Therefore, basic knowledge of the diversity of these microbes in breeds of buffalo is required. Therefore, the methanogenic community in the rumen of Surti buffaloes was analyzed by PCR amplification, cloning, and sequencing of methyl coenzyme $\mathrm{M}$ reductase $(m c r A)$ gene. A total of 76 clones were identified, revealing 14 different sequences (phylotypes). All 14 sequences were similar to methanogens belonging to the order Methanobacteriales. Within Methanobacteriales, 12 clones (6 OTUs) were similar to Methanosphaera stadtmanae and the remaining 8 phylotypes (64 clones) were similar to unclassified Methanobacteriales. Overall, members of the Methanobacteriales dominated the mcrA clone library in the rumen of Surti buffalo. Further studies and effective strategies can be made to inhibit the growth of Methanobacteriales to reduce methane emission from the rumen which would help in preventing global warming.
\end{abstract}

K e y w ords: methyl coenzyme-M reductase, PCR, ruminant methanogens

\section{Introduction}

The rumen is characterized by high microbial population density and complexity of micro-ecological interactions. Methane is biologically produced by the metabolism of a diverse group of methanogenic microorganisms, methanogens, which are phylogenetically placed exclusively as members of the domain archaea. They inhabit typical anaerobic environments, such as wetlands, sediments, geothermal springs and the digestive tracts of mammals (Garcia et al., 2000). Methane is an important greenhouse gas which significantly contributes to global warming. Livestock is a major anthropogenic source of methane emission from agriculture and contributes about $18 \%$ of global greenhouse gas (GHG) emissions, and as much as $37 \%$ of anthropogenic methane, mostly from enteric fermenta- tion by ruminants (FAO, 2006). Livestock rearing has been an integral part of the agricultural system in India. Currently, India possesses the world's largest livestock population of 485 million, which accounts for $13 \%$ of the global livestock population (MOA, 2003). It has $57 \%$ of the world's buffalo and $16 \%$ of the cattle population. The contribution of methane emission in India by buffalo is $42 \%$ (Chhabra et al., 2009).

Several groups have reported the monitoring of methanogen populations from environmental samples through targeting of the 16S ribosomal gene (Yu et al., 2005; Stewart et al., 2006; Wright et al., 2007). While researchers have traditionally used the 16S rRNA gene for phylogenetic diversity, many researches are now addressing the diversity of the methanogenic archaea by studying sequence divergence within the methyl coenzyme-M reductase subunit A ( $m c r A)$ gene (Lueders

* Corresponding author: Ramesh K. Kothari /Krishna M. Singh, Department of Microbiology, Christ College, Rajkot, Gujarat, India; phone 02692 261201; fax 02692 261201; e-mail: kothari.pgpb@gmail.com, e-mail: Kmsingh18@gmail.com 
et al., 2001; Luton et al., 2002; Hallam et al., 2003; Tatsuoka et al., 2004; Rastogi et al., 2008). Methyl coenzyme-M reductase is ubiquitous to methanogens and is crucial to the terminal step of methanogenesis where it is involved in the reduction of the methyl group bound to coenzyme-M. There is no report concerning $m c r A$ genes from buffalo rumen, therefore, we examined the community of methanogens using comparative sequence analysis of the mcrA amplified from total DNA extracted from rumen fluid of Surti buffaloes.

\section{Experimental}

\section{Materials and Methods}

Sampling and DNA extraction. The experiment was carried out on 3 adult Surti buffaloes reared at the Department of Animal Nutrition, College of Veterinary Science and A.H., Anand. All the animals were maintained under uniform feeding regime (I.C.A.R., 1998) for minimum 30 days. The diet consisted of green fodder (Sorghum and NB21), dry mature pasture grass (Dicanthium annulatum) and compound concentrate mixture $(20 \% \mathrm{CP}, 65 \% \mathrm{TDN})$. The animals were offered $10 \mathrm{~kg}$ green, ad-lib dry grass and $2.5 \mathrm{~kg}$ of concentrate mixture daily. Approximately $500 \mathrm{ml}$ of liquor was collected via a stomach tube located in the mid part of the rumen and connected to a vacuum pump at 0, 2, 4 and $6 \mathrm{hrs}$ post feeding (Khampa et al., 2006). About $100 \mathrm{ml}$ liquor was passed through four layers of cheese cloth to remove particulate matter. Remaining liquor was stored at $-80^{\circ} \mathrm{C}$ for further study. Total DNA (each hrs) was extracted separately by using a commercially available kit according to the manufacturer's instructions (QIAGEN Stool kit; QIAGEN, CA). The individual DNA was used as a template in PCR to amplify $m c r A$ gene.

PCR primers and amplification. The $m c r A$ primers used were ME1 (5'-AGCMATGCARATHGGWA TGTC-3-') and ME2 (5'-ATCATKGCRTAGTTDGG RTAGT-3') (Hales et al., 1996), subsequently $\mathrm{mcrA}$ gene were amplified (760 bp) by PCR using metagenomic DNA and Master mix (Fermentas, USA). A total of $25 \mu \mathrm{l}$ of reaction mixture consisted of 10 pmol of each primer, $30 \mathrm{ng}$ of template DNA, $12.5 \mu 1$ of Master mix (Fermentas, USA). The PCR amplification was carried out as follows: 1 cycle at $95^{\circ} \mathrm{C}$ for $3 \mathrm{~min}, 35$ cycles of $95^{\circ} \mathrm{C}$ for $30 \mathrm{~s}, 60^{\circ} \mathrm{C}$ for $1 \mathrm{~min}, 72^{\circ} \mathrm{C}$ for $1 \mathrm{~min}$ and a final elongation at $72^{\circ}$ for $10 \mathrm{~min}$ by using thermal Cycler (ABI, USA). The anticipated product of approximately $760 \mathrm{bp}$ was cleaned separately using a Qiagen DNA Gel Extraction Kits (QIAGEN, CA) in accordance with the directions of the manufacturer and pooled the purified PCR products in equimolar concentration.
Cloning and sequencing. The purified PCR products were cloned in InstaTA cloning kit (Fermentas, USA) as per the instructions of the manufacturer. The recombinant plasmids then were extracted by the Qiagen mini-prep plasmids extraction kit (QIAGEN, CA). Sequencing was performed for all the clones in the library with an ABI Prism 310 Genetic analyser (Applied Biosystems Inc., CA) using BigDye Terminator (version 3.1) at Animal Biotechnology laboratory, AAU, Anand, Gujarat, India.

Sequence analyses and phylogenetic tree construction. All reference sequences were obtained from the Genbank/EMBL/DDBJ (Benson et al., 2007). Sequences ( $\sim 600 \mathrm{bp})$ from the current study were analysed by the CHECK_CHIMERA program (Maidak et al., 2001) to remove any chimeric clone. The similarity searches for sequences were carried out by BLAST (http://www.ncbi.nlm.nih.gov/ BLAST/ Blast.cgi (Madden et al., 1996) and alignment was done using CLUSTAL W (http://www.ebi.ac.uk/ Tools/clustalw2/index.html (Thompson et al., 1994). Ambiguously and incorrectly aligned positions were aligned manually. The distance matrix was calculated using the PRODIST program included in PHYLIP (Felsenstein, 1985) and used to assign sequences in various operational taxonomic units (OTUs) or phylotypes by DOTUR (Schloss and Handelsman, 2005) and total of 14 OTUs were generated. The percentage of good coverage was calculated as $[1-(n / N)]$ X 100, where ' $n$ ' is the number of single clone OTUs and ' $N$ ' is the library size. Phylogenetic tree was constructed by the neighbour joining method using MEGA 4.0 (Tamura et al., 2007). Bootstrap re-sampling analysis for 1000 replicates was performed to estimate the confidence of tree topologies. The prefix mcrA was used to denote OTU identified and nucleotide sequences have been deposited in the Genbank database under the accession numbers GQ120890-GQ120965.

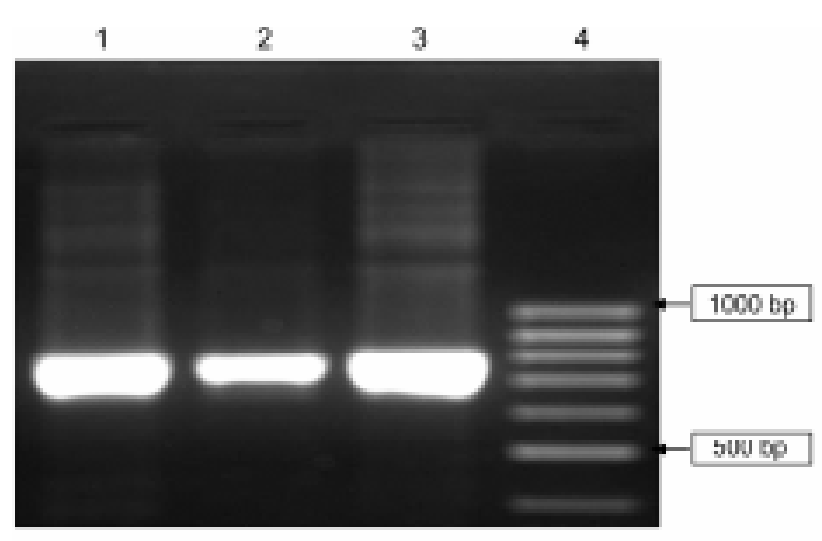

Fig. 1. Ethidium bromide-stained agarose gel showing PCR products (670 bp) amplified from DNAs extracted from the three rumen samples. Template DNAs are as follows: lane 1, sample1; lane 2, sample 2; lane 3; sample 3 and lane 4, shows DNA size marker. 


\section{Results}

Methanogen-specific DNA fragments were amplified from DNA extracted from the Surti rumen fluid by PCR with primers targeting $m c r A$ genes. The amplified fragments from three rumen fluids, which were approx. 760 bp, are shown in Fig. 1. All the clones were subjected to sequence analysis followed by online homology search, Genbank which implements the BLAST algorithm (Madden et al., 1996). None of clone (76) from our library was assigned any genera/species. Because the similarity values of our sequences were too low to assign them to particular taxa with a reasonable degree of confidence. In our library 14 sequences (phylotypes) were generated. Phylogenetic analysis was performed to clarify their taxonomic position. The phylogenetic placements of the deduced DNA sequences are shown in Fig. 2. The good coverage of $m c r A$ library was $94.73 \%$ in present study. This level of coverage showed that the $m c r A$ sequences identified in library represent the majority of methanogen diversity. The sequences obtained in the present study were placed in the single cluster Methanobacteriales.
Table I

Analysis of $m c r A$ gene phylotypes diversity retrieved from the rumen fluid of Surti buffaloes

\begin{tabular}{|l|c|}
\hline \multicolumn{1}{|c|}{ Items } & 16S r DNA library \\
\hline Library size $^{\text {a }}(\mathrm{N})$ & 76 \\
\hline OTUs $^{\mathrm{b}}$ & 14 \\
\hline Single clone OTU $^{\mathrm{c}}(\mathrm{n})$ & 4 \\
\hline Good's coverage $^{\mathrm{d}}(\%)$ & 94.73 \\
\hline Clone distribution $^{\circ}$ & \\
\hline (i) Methanobacteriales & 14 OTUs (76 clones) \\
\hline a Methanosphaera stadtmanae & 6 OTUs (12 clones) \\
\hline b. Unidentified Methanobactriales & 7 OTUs (63 clones) \\
\hline c. Unknown methanogen & 1 OTU (01 clone) \\
\hline
\end{tabular}

${ }^{a}$ Number of clones analyzed from library; ${ }^{b}$ OTUs based on $\mathrm{mcr} A$ gene sequences; ${ }^{\circ}$ OTUs containing only single clone; ${ }^{\mathrm{d}}$ The higher percentage coverage means more diversity is captured

Within the Methanobacteriales, 63 clones (7 OTUs) belonged to the unidentified Methanobacteriales and 12 clones (6 OTUs) sequences were found to be the closest to Methanosphaera stadtmanae. Of the clones isolated from rumen sample, only one clone represented unknown methanogens (Table I).

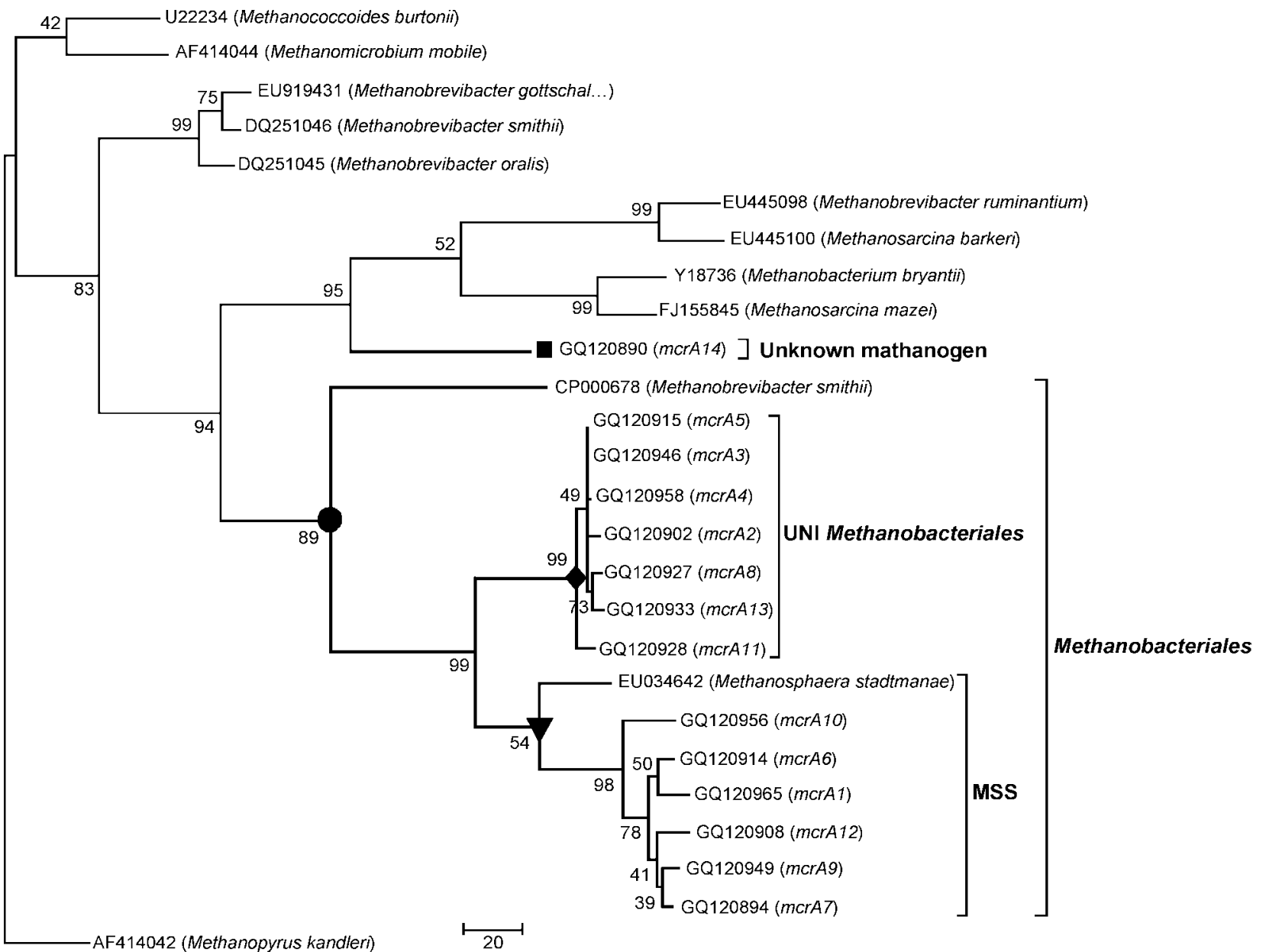

Fig. 2. The evolutionary history was inferred using the Maximum Parsimony method. The bootstrap consensus tree inferred from 1000 replicates is taken to represent the evolutionary history of the taxa analyzed. The percentage of replicate trees in which the associated taxa clustered together in the bootstrap test (1000 replicates) are shown next to the branches. Phylogenetic analyses were conducted in MEGA4. (UNI = unidentified and MSS = Methanosphaera stadtmanae). 


\section{Discussion}

Of 14 phylotypes, 13 sequences (Phylotypes) of the DNA were obtained from the 76 clones in the present study; these sequences were placed in the same cluster, which was relatively close to unidentified Methanobacteriales (63 clone) and M. stadtmanae (12 clones), in phylogenetic placements (Fig. 2). Whitford et al. (2001) also found several sequences that were related to Methanosphaera stadtmanae. Wright et al. (2007) also found a sequence (ON-CAN.13) in cattle from Ontario that was $95.8 \%$ similar to that of Methanosphaera stadtmanae and $99.8 \%$ similar to that of their clone ARC29. Methanogens similar to Methanosphaera stadtmanae have also been reported in pasture-fed dairy cattle (Skillman et al., 2006) The DNA sequences of $m c r A$ genes, isolated in this study, showed similarities with unidentified methanobacteriales and to M. stadtmanae. It has been known that $m c r A$ genes could be used as phylogenetic tool for the specific detection and the identification of methanogenes, because the phylogeny of the $m c r A$ genes and 16S rDNA from the recognized orders of methanogens clearly had strong similarity (Luton et al., 2002).

Our results show that rumen of Surti buffaloes contains one of the essential and diagnostic genes of the methanogenic pathway. The identification of these genes provides a means to identify cluster/group on the basis of $m c r A$ sequence. Moreover, identification of rumen associated $m c r A$ groups defines a functional genomic link between methanogenic and putative reverse methanogenic archaea. Specific questions relating to methanogenic protein function in buffalo rumen await further genomic, biochemical, structural, and proteomic analysis.

\section{Acknowledgements}

Financial support provided by the Department of Biotechnology Govt. of India, New Delhi to conduct the study reported here is acknowledged with respect and gratitude.

\section{Literature}

Benson D.A., I .Karsch-Mizrachi, D.J. Lipman and J. Ostelland. 2007. GenBank. Nucleic Acids Res. 35, D1-D25.

Chhabra A., K.R .Manjunath, S. Panigrahy and J.S. Parihar. 2009. Spatial pattern of methane emissions from Indian livestock. Current Science 96: 5-10.

Felsenstein J. 1985. Confidence limits on phylogenies: an approach using the bootstrap. Evolution 39: 783-791.

FAO, FAOSTAT. 2006. Online Statistical Service, Food and Agriculture Organization of the United Nations, Rome.

Garcia J.L., B.K.C. Patel and B. Olliver. 2000. Taxaonomic, phylogenic, and ecological diversity of methanogenic Archaea. Anaerobe 6: 205-226.

Hales B.A., C. Edwards, D.A. Ritchie, G. Hall, R.W. Pickup and J.R. Saunders. 1996. Isolation and identification of metha- nogen specific DNA from blanket bog peat by PCR amplification and sequence analysis. Appl. Environ. Microbiol. 62, 668-675.

Hallam S.J., P.R. Girguis, C.M. Preston, P.M. Richardson and E.F. DeLong. 2003. Identification of methyl coenzyme M reductase A (mcrA) genes associated with methane-oxidizing archaea. Appl. Environ. Microbiol. 69: 5483-5491.

ICAR. 1998. Nutrient requirements of livestock and poultry. Indian Council of Agricultural Research, New Delhi, India.

Khampa S., M. Wanapat, C. Wachirapakorn and N. Nontaso. 2006. Effects of urea level and sodium di-malate in concentrate containing high cassava chip on ruminal fermentation efficiency, microbial protein synthesis in lactating dairy cows raised under tropical condition. Asian- Aust. J. Anim. Sci. 19: 837-844.

Lueders T., K.J. Chin, R. Conrad and M .Friedrich. 2001. Molecular analyses of methyl-coenzyme $M$ reductase alpha-subunit (mcrA) genes in rice field soil and enrichment cultures reveal the methanogenic phenotype of a novel archaeal lineage. Environ. Microbiol. 3: 194-204.

Luton P.E., J.M. Wayne, R.J. Sharp and P.W. Riley. 2002. The mcrA gene as an alternative to $16 \mathrm{~S}$ rRNA in the phylogenetic analysis of methanogen populations in landfill. Microbiology 148: 3521-3530.

Madden T.L., R.L .Tatusov and J. Zhan. 1996. Application of network BLAST. Meth. Enzymol. 266: 131-141.

Maidak B.L., J.R. Cole, T.G. Lilburn and C.T.P. Jr. 2001. The RDP-II (Ribosomal Database Project). Nucl. Acids Res. 29: 173-174. MOA. 2003. $17^{\text {th }}$ livestock census of India. Department of Animal Husbandry and Dairying, Ministry of Agriculture, Government o India.

Rastogi G., D.R. Ranade, T.Y. Yeole, A.K. Gupta, M.S. Patole and Y.S. Shouche. 2008. Molecular analyses of methanogen diversity associated with cattle dung. World. J. Microbiol. Biotechnol. 24: 2973-2979.

Schloss P.D. and J. Handelsman. 2005. Introducing DOTUR, a compute program for defining operational taxonomic units and estimating species richness. Appl. Environ. Microbiol. 71: $1501-1506$.

Stewart J.A., V.S. Chadwick and A. Murray. 2006. Carriage, quantification, and predominance of methanogens and sulfatereducing bacteria in faecal samples. Lett. Appl. Microbiol. 43: $58-63$.

Skillman L.C., P.N. Evans, C. Strompl and K.N. Joblin. 2006. 16S rDNA directed PCR primers and detection of methanogens in the bovine rumen. Lett. Appl. Microbiol. 42: 222-228.

Thompson J.D., D.G. Higgins and T.J. Gibson. 1994. CLUSTAL W: improving the sensitivity of progressive multiple sequence alignment through sequence weighting, position-specific gap penalties and weight matrix choice. Nucl. Acids Res. 22: 4673-4680. Tatsuoka N., N. Mohammed, M. Mitsumori, K. Hara, M. Kurihara and H. Itabashi. 2004. Phylogenetic analysis of methyl coenzyme-M reductase detected from the bovine rumen. Lett. Appl. Microbiol. 39: 257-260.

Tamura K., J. Dudley, M. Nei and S. Kumar. 2007. MEGA4: Molecular Evolutionary Genetics Analysis (MEGA) software version 4.0. Molecular Biology and Evolution 24: 1596-1599.

Whitford M.F., R.M. Teather and R.J. Forester. 2001. Phylogenetic analysis of methanogens from the bovine rumen. $B M C$ Microbiology 1: 1-5.

Wright A.D.G., C.H. Auckland and D.H. Lynn. 2007. Molecular Diversity of Methanogens in Feedlot Cattle from Ontario and Prince Edward Island, Canada. Appl. Environ. Microbiol. 73: 4206-4210. Yu Y., C. Lee, J. Kim and S. Hwang. 2005. Group-specific primer and probe sets to detect methanogenic communities using quantitative real-time polymerase chain reaction. Biotechnol. Bioeng. 89: 670-679. 